\section{Immuno-Oriented Therapy In The Comprehensive Treatment Of Acute Pancreatitis}

Safarov S.S.

\author{
Bukhara State Medical Institute, Bukhara branch of the \\ Republican Scientific Center for Emergency Medicine, \\ Uzbekistan
}

\author{
G OPEn ACCESS \\ The American Journal of \\ Medical Sciences And \\ Pharmaceutical \\ Research \\ JULY 2020 \\ Page No.: 105-111 \\ Volume-II Issue-VII \\ PUBLISHED: 31 JULY 2020 \\ www.usajournalshub.com/inde \\ x.php/TAJMSPR \\ Copyright: Original content \\ from this work may be used \\ under the terms of the \\ Creative Commons Attribution \\ 4.0 licence.
}

\title{
Abstract
}

The immuno-oriented effects of polyoxidonium and immunoglobulin in the complex treatment of patients with acute pancreatitis were studied. Patients with acute pancreatitis from the first days of the disease revealed violations of the immune status in the form of the development of immunodeficiency. Complex therapy, including immunomodulin or polyoxidonium, allowed approximation of the level of cytokines to those of healthy donors. Studies allow us to recommend the inclusion of polyoxidonium and immunomodulin in the basic, comprehensive conservative therapy of patients with acute pancreatitis for the purpose of immunocorrective therapy.

Key words: acute pancreatitis, immune response.

\section{Introduction}

Acute pancreatitis (AP) is a destructive process of pancreatic tissue of varying severity. Considering AP as a time-evolving process, during which a regular change in the periods and phases of the disease is observed, a number of complications typical for both the pancreatogenic toxemia phase and the phase of destructive complications can be distinguished. Syndrome of a systemic inflammatory reaction (SSIR) can occur in any phase of the course of pancreatitis and be the main syndrome, while completely different mechanisms will determine its path genetic basis $[12,14]$. In general, SSIR is the absolute 
normal response to invasion. However, due to the over activity of the ongoing processes, the SSVR can jeopardize the functioning of various organs and systems, which leads to the syndrome of multiple organ failure $[7,8]$. To date, it is known that the leading role in the pathogenesis of AP is played by inflammatory mediators: pro-inflammatory cytokines, such as IL-1, IL-6, IL-8 and TNF-a $[1,10]$. The results of their influence are an increase in vascular permeability, leukocyte migration, local tissue damage, generalization of the inflammatory reaction, damage to the organs of natural detoxification with the development of multiple organ failure $[2,9]$. When the immune system fights against infectious agents, cytokines signal immune cells, such as T-lymphocytes and macrophages, so that they go to the site of infection. In addition, cytokines stimulate cells to produce even greater cytokines. This positive feedback becomes uncontrolled, and too many activated immune cells accumulate in one place. Thus, the mechanism by which the release of a large number of cytokines contributes to the progression of severe SSIR during AP becomes clear[13]. The use of drugs with immunotropic activity in patients with AP has opened up new opportunities for increasing the effectiveness of conservative therapy, surgical interventions for patients with AP, and decreasing mortality and length of stay in the hospital [3-5]. The great interest are the preparations of the polypeptide nature - polyoxidonium and immunomodulin. The first has a pronounced immunomodulation, detoxifying, membrane-stabilizing and antioxidant activity, reduces the cytotoxicity of chemical, medicinal substances and infectious agents. The use of polyoxidonium in the complex treatment of a number of surgical diseases makes it possible to increase the effectiveness of therapy, reduce the dose of antibacterial agents, and reduce the duration of treatment [5]. Immunomodulin - domestic immunostimulant (Manufacturer Immunized OOO, Uzbekistan), in the form of a solution for injection of $0.01 \% 1 \mathrm{ml}$., Which contains a complex of high-quality natural thymic peptides or their analogues $100 \mu \mathrm{g}$. Presenting a complex of high-quality natural thymic peptides or their analogues, immunomodulin corrects the functions of the immune system, stimulates the production of endogenous interferon, the liver detoxification system, regeneration processes, erythro- and leukopoiesis, and restores the biorhythms of the immune system. In secondary immunodeficiency states, immunomodulin restores blood levels of Tlymphocytes, T-suppressors, T-helpers, phagocytes and reduces the intensity of cellular immune responses directed against its own organs and tissues, stimulates the immune response against infectious agents (viruses, fungi, bacteria, parasites), detoxification processes in the liver, as well as the regeneration of body tissues. The drug is compatible with antibiotics and other drugs of basic therapy. Immunotherapy is a necessary component of the treatment of acute pancreatitis along with basic therapy.

Purpose of work - to study the immune-oriented effects of polyoxidonium and immunomodulin in the complex therapy of patients with AP.

\section{Material and methods}

We observed 82 patients (45 men and 37 women) with OP, a comprehensive clinical, laboratory and instrumental examination and treatment of which was carried out in the surgical department of the Bukhara branch of the REMTC, the Republic of Uzbekistan. The 
duration of the disease until hospitalization varied from several hours to 3 days. Clinical and laboratory signs of SSIR were revealed during an initial examination in 5 patients with edematous form of $A P$ and in all patients with acute destructive pancreatitis (ADP). Treatment of all patients was carried out with the inclusion of antisecretory (contriver, octreotide, quamatel) and infusion therapy. In accordance with the generally accepted classification, the patients were divided into 3 randomized groups by sex, age and treatment: the 1st group comprised 26 patients (17 with edematous pancreatitis and 9 with small focal pancreatic necrosis) who received treatment that did not include immunocorrective drugs with infusion and analgesics; H2-histamine receptor blockers quamatel; antibacterial therapy - cefaperazone-sulbactam, amikacin); Group 2 - 28 patients (19- with edematous pancreatitis and 9 - with small focal pancreatic necrosis) who additionally received polyoxidonium (100 mg intramuscularly 10 times, after 24 hours); group 3 included 28 patients (19- with edematous pancreatitis and 9 - with small focal pancreatic necrosis) who received immunomodulin as a part of complex treatment (100 $\mu \mathrm{m}$ intramuscularly, one injection daily, 10 injections, in a daily dose of $1.0-1,5 \mathrm{mcg}$ / kg) .. The control group of patients consisted of 20 healthy donor volunteers of the same age.

The work examined the immune status of patients and healthy individuals using test kits of I and II levels according to R.V. Petrov. The lymphocyte phenotype was determined by enzyme-linked immunosorbent assay using monoclonal antibodies (Sorbent LLC, Moscow) to the structures CD3 (total T-lymphocytes), CD22 (B-lymphocytes), CD4 (T-helpers), CD8 (cytotoxic cells) , CD16 (NK cells), CD25 (receptor for IL-2). The content of immunoglobulins of classes $M, G, A$. Determination of the content of pro-inflammatory (TNFa, IL-1, IL-6, IL-4) cytokines in the serum of peripheral blood was carried out before treatment, on days 1-3, 4-7 days, later 7 days with conservative therapy of the edematous form of AP and at the same time after surgery for acute destructive pancreatitis (ADP). The determination of the level of cytokines was carried out in the Immunology and Reproduction Laboratory of the Institute of Human Immunology and Genomics of the Academy of Sciences of the Republic of Uzbekistan, by enzyme-linked immunosorbent assay ELISA ("Cytokine" Scientific Research Institute of General Medicine, St. Petersburg).

\section{Results}

The results of a study of the immune status of patients with AP showed that before treatment, the absolute and relative content of total T-lymphocytes (CD3 +), T-helper $(\mathrm{CD} 4+)$ and cytotoxic (CD8 + ) subpopulations, relative content of NK cells (CD16 + ) were significantly reduced. The percentage of cells expressing early (CD25 +) activation markers was increased, as well as the relative and absolute level of B-lymphocytes (CD22 + ). Against the background of traditional treatment, an increase in the percentage and absolute number of total T-lymphocytes even in comparison with healthy donors, normalization of the content of CD4 + and CD8 + lymphocytes was established, while the level of $\mathrm{CD} 16+, \mathrm{CD} 25+, \mathrm{CD} 22+$ lymphocytes remained the same as in patients before treatment. 
THE AMERICAN JOURNAL OF MEDICAL SCIENCES AND PHARMACEUTICAL RESEARCH

ISSN (e): 2689-1026

DOI: https://doi.org/10.37547/TAJMSPR/Volume02Issue07-13

Table1.

Indicators of cellular immunity in the peripheral blood of patients with AP $(\mathbf{M} \pm \mathbf{m})$

\begin{tabular}{|c|c|c|c|c|c|c|c|}
\hline \multirow{2}{*}{$\begin{array}{l}\text { Patient } \\
\text { groups }\end{array}$} & \multirow[b]{2}{*}{$\mathbf{n}$} & \multicolumn{6}{|c|}{ T-cells } \\
\hline & & CD3+ & CD4+ & CD8+ & CD16+ & CD25+ & CD22+ \\
\hline & & $\%$ & $\%$ & $\%$ & $\%$ & $\%$ & $\%$ \\
\hline Control & 20 & $\begin{array}{l}24,3 \pm \\
2,5\end{array}$ & $\begin{array}{l}38,1 \pm \\
3,1\end{array}$ & $\begin{array}{l}22,1 \pm 2, \\
3\end{array}$ & $\begin{array}{l}11,6 \pm 2, \\
2\end{array}$ & $\begin{array}{l}13,8 \pm 1 \\
4\end{array}$ & $\begin{array}{l}21,4 \pm 1, \\
8\end{array}$ \\
\hline $\begin{array}{l}\text { Patients } \\
\text { with AP }\end{array}$ & 82 & $\begin{array}{l}16,7 \pm \\
2,3\end{array}$ & $\begin{array}{l}24,1 \pm 2 \\
, 5\end{array}$ & $\begin{array}{l}16,9 \pm 2, \\
1\end{array}$ & $7,9 \pm 1,3$ & $\begin{array}{l}29,2 \pm 1, \\
2\end{array}$ & $\begin{array}{l}39,1 \pm 2, \\
4\end{array}$ \\
\hline
\end{tabular}

The use of immunomodulin normalized the relative and absolute levels of CD3 + cells, the absolute number of B-lymphocytes and the percentage of T-helpers, NK cells and cells expressing early activation markers, while the absolute content of CD4 + remained reduced even compared to traditional treatment and CD8 + lymphocytes, the percentage of T-helpers and B-lymphocytes was the same as after traditional treatment.

\section{Table2.}

Indicators of cellular immunity in the peripheral blood of patients with AP as a result of immune-oriented therapy $(M \pm m)$

\begin{tabular}{|c|c|c|c|c|c|c|c|}
\hline \multirow[b]{2}{*}{$\begin{array}{l}\text { Patient } \\
\text { groups }\end{array}$} & \multirow[b]{2}{*}{$\mathbf{n}$} & \multicolumn{6}{|c|}{ Т-клетки } \\
\hline & & $\begin{array}{l}\text { CD3 } \\
+\end{array}$ & CD4+ & CD8+ & CD16+ & CD25+ & CD22+ \\
\hline & & $\%$ & $\%$ & $\%$ & $\%$ & $\%$ & $\%$ \\
\hline $\begin{array}{l}\text { Tradition } \\
\text { al } \\
\text { treatment } \\
\text { TT }\end{array}$ & 26 & $\begin{array}{l}23,8 \pm \\
2,6\end{array}$ & $\begin{array}{l}39,3 \pm \\
2,1\end{array}$ & $23,7 \pm 2,6$ & $11,8 \pm 2,4$ & $13,4 \pm 1,2$ & $21,9 \pm 1,6$ \\
\hline $\begin{array}{l}\text { TT } \\
\text { immunom } \\
\text { odulin }\end{array}$ & 28 & $\begin{array}{l}24,6 \pm \\
2,2\end{array}$ & $\begin{array}{l}30,1 \pm 2 \\
7\end{array}$ & $22,9 \pm 2,3$ & $12,9 \pm 1,3$ & $13,2 \pm 1,2$ & $\begin{array}{l}19,9,1 \pm 2 \\
4\end{array}$ \\
\hline $\begin{array}{l}\text { TT+ } \\
\text { polyoxido } \\
\text { nium }\end{array}$ & 28 & $\begin{array}{l}23,6 \pm \\
2,3\end{array}$ & $\begin{array}{l}38,7 \pm 3 \\
3\end{array}$ & $22,6 \pm 2,5$ & $10,3 \pm 1,4$ & $12,3 \pm 1,4$ & $22,8 \pm 2,9$ \\
\hline
\end{tabular}

After the use of polyoxidonium, the relative and absolute contents of CD3 + CD4 +, $\mathrm{CD} 8+, \mathrm{CD} 22+$ cells did not differ from healthy donors, with the exception of CD16 + and CD25 + lymphocytes, the level of which was lower than in the control group.

At the time of admission to the hospital, as well as after various treatment regimens, the concentration of IgM was not significantly changed. The content of IgG, IgA was increased. Conventional therapy reduced the level of IgG, and increased the concentration of IgA compared with the parameters of patients before treatment, but 
normalization of the indicators did not occur. The inclusion of immunomodulin in complex conservative therapy reduced the level of IgG to the level of healthy donors, the content of IgA changed in the same way as in the group of patients who received conventional treatment. Polyoxidonium normalized the concentration of IgG, IgA. At the time of admission, in patients with AP, a significant increase in the plasma level of the main dominant secretory form of IL-1, namely, IL-1 (2.1 times), which is the main mediator of the development of the local inflammatory reaction, an acute phase response to the level of the body, was detected [9].

Conventional treatment and with the inclusion of immunomodulinane altered the increased plasma level of IL-1. The normalization of the indicator occurred only under the influence of polyoxidonium.

\section{Table 3}

The content of peripheral blood cytokines in patients with AP in the dynamics of complex and immuno-oriented therapy $(\mathbf{M} \pm \mathbf{m})$

\begin{tabular}{|c|c|c|c|c|c|}
\hline Cytokines & $\begin{array}{l}\text { Before } \\
\text { Treatme } \\
\text { nt } \\
n=82\end{array}$ & $\begin{array}{l}\text { Conventi } \\
\text { onal } \\
\text { treatmen } \\
\text { t } \\
n=26\end{array}$ & $\begin{array}{l}\text { CT+ } \\
\text { immunomo } \\
\text { dulin } n= \\
28\end{array}$ & $\begin{array}{l}\text { CT } \\
\text { polyoxidoniu } \\
\text { m } \\
n=28\end{array}$ & $\begin{array}{l}\text { Control } \\
n=20\end{array}$ \\
\hline $\begin{array}{l}\text { FNOa,pg/ } \\
\mathrm{ml} \\
\mathrm{IL}-1, \\
\mathrm{pg} / \mathrm{ml} \\
\mathrm{IL}-6, \\
\mathrm{pg} / \mathrm{ml} \\
\mathrm{IL}-4, \mathrm{pg} / \mathrm{ml}\end{array}$ & $\begin{array}{l}62,2 \pm 2, \\
0 \\
65,8 \quad \pm \\
1,2 \\
43,5 \quad \pm \\
8,7 \\
58,7 \pm \\
1,2\end{array}$ & $\begin{array}{c}32,2 \pm 0,5 \\
56,9 \pm 1,40 \\
29,7 \pm 1,1 \\
36,5 \pm 1,4\end{array}$ & $\begin{array}{l}23,1 \pm 1,4 \\
45,1 \pm 0,2 \\
18,2 \pm 9,8 \\
16,8 \pm 1,2\end{array}$ & $\begin{array}{l}18,1 \pm 1,2 \\
35,1 \pm 0,2 \\
17,2 \pm 9,8 \\
14,9 \pm 1,4\end{array}$ & $\begin{array}{l}10,9 \pm 0, \\
5 \\
32,1 \pm 0, \\
2 \\
16,3 \pm 0, \\
6 \\
14,2 \pm 4, \\
5\end{array}$ \\
\hline
\end{tabular}

The level of TNFa, the primary inflammatory mediator that plays a significant role in coordinating the inflammatory response and the cytokine cascade, for example, IL-1, IL-6, and IL-4, increased even more (5.6 times) in patients with AP. Traditional treatment by almost $50 \%$ reduced the concentration of $\mathrm{TNFa}$, the use of immunomodulin similarly affected the studied parameter, polyoxidonium was more effective, against which the concentration of TNFa decreased to a greater extent, but not to the level of healthy donors. An increase in IL- 6 in the blood plasma of patients at the time of admission was 2.6 times. Traditional treatment reduced its content, but not to the level of the control group. In groups of patients who received polyoxidonium as part of complex immunomodulin therapy, IL-6 concentration returned to normal. Numerous biological functions of IL-4 include the induction of switching immunoglobulin production by plasma cells to IgE production and stimulation of a subpopulation of T-helper cells (Th2) of the second type. In our observations, the level of IL-4 in patients with AP at the time of admission was 4.2 times higher than in healthy donors. As in previous cases, after 
traditional treatment, the concentration decreased, but not to the normal level, after complex therapy, including immunomodulin or polyoxidonium, the level of cytokine did not differ from that of healthy donors.

Thus, in patients with acute pancreatitis, significant violations of the immune status were detected. The data obtained largely overlap with the works of a number of authors written out in the picture of a systemic inflammatory response $[11,13,14]$. The results of our studies allow us to recommend the inclusion in the basic, complex conservative therapy of patients with AP, polyoxidonium and immunomodulin for the purpose of immune-oriented therapy.

\section{Conclusion}

1. With AP, pathological changes in organs and systems are generalized and are manifested by a systemic inflammatory reaction syndrome.

2. In patients with acute pancreatitis from the first days of the disease, violations of the immune status are detected in the form of the development of immunodeficiency.

3. The need for control of developing SSIR in AP is obvious and leads to the search for new points of application of therapeutic measures.

4. The obtained research results allow us to recommend the inclusion of polyoxidonium and immunomodulins in the basic, comprehensive conservative therapy of patients with OP for the purpose of immune-oriented therapy.

\section{References}

1. Averkiev V. L., Tarasenko V. S., Latysheva T. V. et al. Changes in some immunological parameters in pancreatic necrosis and their correction // Surgery. 2003. No. 5. P. 31-34.

2. Blagovestnov D.A. Et al., Prognostic significance of the parameters of the immune response in the treatment of patients with acute pancreatitis, "Bulletin of new technologies" - 2006 - T. XIII, No. 1 - p. 67

3. Bulava G.V., Abakumov M.M., Borovkova N.V. et al. Assessment of the severity of immune disorders and prediction of the development of purulent-septic complications in patients with emergency surgical pathology // Tomsk State University Journal. Surgery them. I.I. Grekov. 2009.Vol. 168, No. 3. P. 10-16.

4. Borovkova N.V. Secondary immunodeficiency in purulent-septic complications of surgical diseases: author. dis... doc. med. sciences. M., 2011.49 s.

5. Ermolov A. S., Borovkova N. V., Ivanov P. A. et al. Immunological assessment of severity and prognosis of acute pancreatitis // Vestn. Surgery them. I.I. Grekov. 2005.V. 164, No. 6. S. 22-28.

6. Tolstoy A. D., Popovich A. M. Immune disorders and methods of immuno-oriented therapy in acute destructive pancreatitis // Terramedica. 2003. No. 4. P. 28-31.

7. SvistunovN. N., Ivlev VV On the possibility of predicting the outcomes of acute pancreatitis with a severe course., "Bulletin of the St. Petersburg University.", Ser. 11. 2009. Issue. 3 
8. Litvin A. A., Current opportunities for predicting infectious complications of severe pancreatitis (literature review)., "Bulletin of the St. Petersburg University.", Ser. 11. 2009. Issue. 3

9. Shilyaev A. V. Prediction of purulent complications in acute destructive pancreatitis taking into account immune disorders and their correction: Diss. Candidate of Medical Sciences: "Military Medical Academy" .- St. Petersburg, 2007.- 112 pp., ill.

10. Hietaranta A., Mustonen H. Puolakkainen P. et al. Proinflammatory effects of pancreatic elastase are mediated trough TLR4 and NF-kB // Biochem. Biophys. Res. Commun. - 2004. -Vol. 323, No. 1. - P. 192-196.

11. Hong-GuangLi; Zong-GuangZhou; Yuan Li. Alterations of Toll-like Receptor 4 Expression on Peripheral Blood Monocytes During the Early Stage of Human Acute Pancreatitis // Digestive Diseases and Sciences. Published online: April 6, 2007.

12. Kylanpaa-Back M. L., Takala A., Kemppainen E. Cellular markers of systemic inflammation and immune suppression in patients with organ failure due to severe acute pancreatitis // Scand. J. Gas-troent. 2001. Vol. 36 (10). P. 1100-1107. SabroeI., Parker L.C., DowerS.K., WhyteM.K. The role of TLR activation in inflammation // J. Pathol. 2008. - Vol. 214, No. 2. - P. 126-135.

13. UlloaL., TraceyK.J. The 'cytokine profile ': a code for sepsis // Trends Mol. Med. 2005. -Vol. 11. - P. 56-63.

14. Weber C.K., Adler G. From acinar cell damage to systemic inflammatory response: current concepts in pancreatitis // Pancreatology. - 2001. - Vol. 1. -P. 356-362. 